\title{
Nerve Growth Factor Serum Levels Are Associated With Regional Gray Matter Volume Differences in Schizophrenia Patients
}

\author{
Kristina Neugebauer ${ }^{1,2 *}$, Christine Hammans ${ }^{1,2}$, Tobias Wensing ${ }^{1}$, Vinod Kumar ${ }^{1,2,3}$, \\ Wolfgang Grodd ${ }^{3}$, Lea Mevissen 1,2, Melanie A. Sternkopf ${ }^{1,2}$, Ana Novakovic ${ }^{1,2}$, Ted Abel ${ }^{4}$, \\ Ute Habel ${ }^{1,2}$ and Thomas Nickl-Jockschat ${ }^{1,2,4,5}$ \\ ${ }^{1}$ Department of Psychiatry, Psychotherapy and Psychosomatics, Medical Faculty, RWTH Aachen University, Aachen, \\ Germany, ${ }^{2}$ Jülich-Aachen Research Alliance, Jülich, Germany, ${ }^{3}$ Max-Planck-Institute for Biological Cybernetics, Tübingen, \\ Germany, ${ }^{4}$ lowa Neuroscience Institute, University of lowa, lowa City, IA, United States, ${ }^{5}$ Department of Psychiatry, Carver \\ College of Medicine, University of lowa, lowa City, IA, United States
}

\section{OPEN ACCESS}

Edited by:

Unn Kristin Haukvik,

University of Oslo,

Norway

Reviewed by:

Anilkumar Pillai,

Georgia Regents Medical Center,

United States

Kjetil Nordbø Jørgensen,

Diakonhjemmet Hospital, Norway

*Correspondence:

Kristina Neugebauer

kneugebauer@ukaachen.de

Specialty section:

This article was submitted to

Schizophrenia,

a section of the journal

Frontiers in Psychiatry

Recieved: 06 August 2018

Accepted: 10 April 2019

Published: 26 April 2019

Citation:

Neugebauer K, Hammans C, Wensing T, Kumar V, Grodd W,

Mevissen L, Sternkopf MA,

Novakovic A, Abel T, Habel $U$ and

Nickl-Jockschat T (2019) Nerve Growth Factor Serum Levels Are

Associated With Regional Gray

Matter Volume Differences in

Schizophrenia Patients.

Front. Psychiatry 10:275.

doi: 10.3389/fpsyt.2019.00275
Numerous neuroimaging studies have revealed structural brain abnormalities in schizophrenia patients. There is emerging evidence that dysfunctional nerve growth factor (NGF) signaling may contribute to structural brain alterations found in these patients. In this pilot study, we investigated whether there was a correlation between NGF serum levels and gray matter volume (GMV) in schizophrenia patients. Further, we investigated whether there was an overlap between the correlative findings and cross-sectional GMV differences between schizophrenia patients $(n=18)$ and healthy controls $(n=19)$. Serum NGF was significantly correlated to GMV in the left prefrontal lobe, the left midcingulate cortex, and the brainstem in schizophrenia patients. However, we did not find any correlations of NGF serum levels with GMV in healthy controls. Schizophrenia patients showed smaller GMV than healthy controls in brain regions located in the bilateral limbic system, bilateral parietal lobe, bilateral insula, bilateral primary auditory cortex, left frontal lobe, and bilateral occipital regions. In a conjunction analysis, GMV in the left midcingulate cortex (MCC) appears negatively correlated to NGF serum levels in the group of schizophrenia patients and also to be reduced compared to healthy controls. These results suggest an increased vulnerability of schizophrenia patients to changes in NGF levels compared to healthy controls and support a role for NGF signaling in the pathophysiology of schizophrenia. As our pilot study is exploratory in nature, further studies enrolling larger sample sizes will be needed to further corroborate our findings and to investigate the influence of additional covariates.

Keywords: schizophrenia, nerve growth factor, voxel-based morphometry, neuroimaging, functional decoding

\section{INTRODUCTION}

Structural brain abnormalities in schizophrenia patients have been repeatedly demonstrated by neuroimaging studies and were robustly confirmed by numerous meta-analyses $(1-8)$, supporting the hypothesis that schizophrenia is associated with altered cerebral connectivity and morphology (9-11). The most consistent gray matter abnormalities were found in fronto-temporo-thalamic 
regions lateralized to the dominant hemisphere $(3,5,6,8,12$, 13). Notably, these changes were reported to be evident in first episode patients (14-18) and to be more pronounced with increased duration of the illness and earlier age of onset $(2-3,4$, $6,8,12,17,19-24)$. Gray matter reductions were also frequently reported-although with lesser consistency-for cerebellar (21, $25)$, occipital $(26,27)$, and parietal $(1,4,28)$ structures.

Anatomically, decreased amounts of cortical neuropil, deficits in dendritic arborization, and cortical afferents were reported to be contributing volume reductions in schizophrenia (29-33). In some brain areas, gray matter volume (GMV) reduction partially can be explained by a decrease in synaptic conjunctions $(34,35)$. This relation was investigated particularly for the dorsolateral prefrontal cortex and suggests influence on cognitive functions in schizophrenia patients $(34,36)$.

It seems likely that the etiopathogenesis of the structural differences found in schizophrenia patients is multifactorial and related to different interacting pathophysiological mechanisms (37). Members of the neurotrophin protein family, including nerve growth factor (NGF), have been repeatedly implicated not only in the pathogenesis of schizophrenia per se, but are plausible candidates to be involved also in the development of these neuroanatomical anomalies (38-40). Consequently, neurotrophins with their crucial role of contributing to the survival of neurons and the reorganization of neural circuits appear as worthwhile candidates to be studied in brain structural changes in schizophrenia.

NGF is essentially involved in neural development, differentiation, and maintenance of neurons not only in development, but throughout life, and has both short-time and long-term effects on brain structure and function by inducing neurite outgrowth as well as the length and complexity of dendritic length in cortical neurons $(38,39,41-45)$. Although only few studies have investigated correlations between NGF levels in the peripheral blood and the central nervous system, several lines of evidence suggest that peripheral NGF serum levels allow valid conclusions on central nervous concentrations. Animal studies have shown that NGF penetrates the blood-brain barrier $(46,47)$ significantly better than albumin or IgG (48). In particular, NGF has been pointed out as the neurotrophin with the fastest passage of the blood-brain barrier in a mouse model (49). These properties render peripheral NGF as one of the most promising candidates within the neurotrophin family to infer on central levels. Recent evidence points to a reliable correlation between peripheral and central nervous NGF levels in humans, at least in healthy controls (50). Although further studies on larger collectives are warranted to corroborate these findings, we regard this as a highly encouraging lead that findings from animal models might be translatable to humans. Moreover, several studies have reported associations between peripheral NGF levels and various aspects of schizophrenia pathophysiology. For example, in schizophrenia patients, peripheral NGF levels were reported to be correlated with abnormal electrophysiological measures, namely p300 (51), while antipsychotic treatment was associated with an increase in NGF serum levels (24). Considering these findings, NGF serum levels may be a highly promising marker for central NGF concentrations.
NGF dysfunction, either due to pathological alteration of its concentration or its action on the receptor may contribute to impaired neuronal development, neuroplasticity, and synaptic disconnections. These changes may underlie structural and functional alterations observed in schizophrenia (52-54).

NGF serum levels in schizophrenia patients have been repeatedly reported to be significantly reduced when compared to healthy subjects $(54,55)$. Besides decreased NGF levels in the peripheral blood, decreased levels of NGF in the cerebrospinal fluid (CSF) (50) and decreased levels of NGF receptors (56), elevated NGF autoantibodies (57), and altered NGF gene expression (56) have been observed. Thus, changes of NGF levels might be involved in the formation of structural brain alternation of schizophrenia $(24,53)$.

While studies actually are still scarce, pioneer studies suggest a putative influence of neurotrophins on neural structure in schizophrenia patients. For example, a correlation was found between NGF autoantibodies in serum and total volume of the frontal lobe in schizophrenia patients (58). Another study explored the impact of the BDNF Val66Met gene variant in schizophrenia. This single nucleotide polymorphism (SNP) maps to the neurotrophin precursor protein of BDNF (brainderived neurotrophin factor) (proBDNF) and is correlated with BDNF serum levels (59). Val66Met genotype was shown to correlate with reduced GMV in temporal and occipital regions known to be associated with verbal memory and visuospatial abilities in schizophrenia patients as well as healthy subjects (60). Another study suggests a contribution of the age-related decline of BDNF serum levels to hippocampal volume as well as memory decline in late adulthood (61). In patients with systemic lupus erythematosus with neuropsychiatric manifestation, immune cell NGF levels were found to be correlated with brain atrophy reflected by lateral ventricle enlargement and thalamic volume loss (62).

This study aimed to investigate a potential correlation between NGF serum levels and brain structural differences in schizophrenia. Furthermore, a potential overlap between the results of a whole brain correlation analysis between GMV and NGF serum levels and the results of GMV reductions in schizophrenia patients were identified in a conjunction analysis.

\section{MATERIALS AND METHODS}

\section{Subjects}

Eighteen schizophrenia patients from the Department of Psychiatry, Psychotherapy and Psychosomatics, University Hospital RWTH Aachen, Aachen, Germany, and 19 gender- and age-matched healthy controls from the general population participated in the present study (Table 1). All subjects were of Caucasian descent and right-handed. Diagnosis of schizophrenia was established using the International statistical classification of diseases and related health problems (ICD-10) diagnostic criteria (code F20.X). Symptom severity in schizophrenia patients was measured using the Positive and Negative Syndrome Scale (PANSS) (63). Exclusion criteria for all subjects were 1) current substance or alcohol abuse or any diagnosed substance abuse or addiction in the past 
TABLE 1 | Demographic and clinical characteristics of the study subjects.

\begin{tabular}{|c|c|c|c|}
\hline & sz & $\mathrm{HC}$ & Statistics \\
\hline $\mathrm{N}$ & 18 & 19 & \\
\hline \multicolumn{4}{|l|}{ Demographics } \\
\hline Age (years) & $36.94 \pm 9.90$ & $35.79 \pm 11.56$ & $t=-.326, p=.747$ \\
\hline Gender (female/male) & $7 / 11$ & $7 / 12$ & $\chi^{2}=.016, p=.898$ \\
\hline Education (years) & $16.17 \pm 4.32$ & $18.79 \pm 3.91$ & $t=1.939, p=.061$ \\
\hline $\mathrm{BMI}$ & $27.08 \pm 4.91$ & $25.04 \pm 5.05$ & $z=-1.383, p=.169$ \\
\hline \multicolumn{4}{|l|}{ Biophysiology } \\
\hline Smokers/ex-smokers & $9 / 0$ & $1 / 1$ & \\
\hline Nicotine (pack-years) & $10.61 \pm 15.97$ & $4.63 \pm 14.64$ & $z=-1.853, p=.061$ \\
\hline Sports (h/week) & $1.75 \pm 1.99$ & $4.34 \pm 3.5$ & $z=2.825, p=.004$ \\
\hline NGF $(\mathrm{pg} / \mathrm{ml})$ & $.0546 \pm .005$ & $.0574 \pm .007$ & $z=-1.401, p=.169$ \\
\hline \multicolumn{4}{|l|}{ Clinical } \\
\hline Duration illness (years) & $12.58 \pm 9.67$ & & \\
\hline \multicolumn{4}{|l|}{ PANSS } \\
\hline Positive & $15.33 \pm 6.17$ & & \\
\hline Negative & $23.61 \pm 9.56$ & & \\
\hline General & $43.83 \pm 15.77$ & & \\
\hline Total & $84.78 \pm 29.13$ & & \\
\hline \multicolumn{4}{|l|}{ Medication } \\
\hline OLZ (mg/day) & $22.14 \pm 11.94$ & & \\
\hline Atypicals (\%) & $100 \%$ & & \\
\hline Atypicals mono & $56 \%$ & & \\
\hline Atypicals combi & $33 \%$ & & \\
\hline Atypical plus typical & $11 \%$ & & \\
\hline
\end{tabular}

SZ, schizophrenia patients; HC, healthy controls; n, number of subjects per group; BMI, body mass index; pg, pictogram; OLZ, olanzapine equivalent; atypical, atypical antipsychotic; mono, monotherapy; combi, combi-therapy; typical, typical antipsychotic. Values are mean $\pm S D$.

(ICD-10: F10.1 or .2 - 19.1 or .2), 2) severe medical conditions such as chronic or acute diseases (i.e., infections, allergies), 3) general contraindications to MRI scanning, 4) gross morphological changes on MRI such as cerebral atrophy, hydrocephalus, or previous injury, and 5) incomplete scanning. Subjects treated with benzodiazepines were not included, except the drug was at least in its second elimination half-life period after intake. Additional exclusion criteria for the healthy control subjects included any personal or family history of psychiatric disorders in first-degree relatives. The study protocol was approved by the local ethics committee of the RWTH Aachen University. Before being enrolled in the study, written informed consent was obtained from each subject in accordance with the Declaration of Helsinki.

\section{Clinical Measures}

We systematically assessed clinical variables, such as duration of disease and medication, by a detailed medical interview. Also, lifestyle habits such as smoking and weekly amount of physical activity were assessed, considering that these factors may influence the outcome of the disease and the neurotrophin levels (64-67). For antipsychotic medication, equivalent dose of olanzapine was calculated by using the conversion scale proposed by Gardner and colleagues (68). As antipsychotic medication (24) and body mass index (BMI) (69) have been shown to exert an influence on NGF serum levels, we explored whether these parameters were correlated in the entire sample, and the schizophrenia patients, as well as the healthy controls alone.

\section{NGF Serum Level Assessment and Analysis}

Subjects were allowed to have their usual breakfast in the morning. A venous blood sample of $10 \mathrm{ml}$ was collected in serum tubes from all subjects at 8:00 AM to control for circadian changes in NGF levels (70). Subsequently, serum was obtained after centrifugation at $2,000 \mathrm{rpm}$ for $10 \mathrm{~min}$ at room temperature and then stored at $-80^{\circ} \mathrm{C}$ in polypropylene tubes until analysis to avoid adhesion of NGF to the tube surface (71). Mature/ biological active beta-NGF serum levels were measured with a double antibody sandwich enzyme-linked immunosorbent assay (ELISA) using a commercial kit (Human NGF/NGF Beta PicoKine $^{\mathrm{TM}}$ ELISA Kit, Boster Biological Technology Co., Inc., USA) according to the manufacturer's instructions ${ }^{1}$. The assay has a sensitivity of $<1 \mathrm{pg} / \mathrm{ml}$; the assay range comprises $15.6-$ $1,000 \mathrm{pg} / \mathrm{ml}$. For each sample, standard and blank control were carried out in duplicate by trained research personnel and the results were averaged.

\section{Magnetic Resonance Imaging Data Acquisition and Processing}

Imaging was performed immediately after the acquisition of the individual blood samples on a Siemens Trio 3T MRI scanner (Siemens Medical Systems, Erlangen, Germany) using a 32-channel head coil. A T1-weighed magnetization prepared rapid acquisition gradient echo (MP-RAGE) sequence that was

${ }^{1}$ https://www.bosterbio.com/picokine_elisa_kit_datasheet.php?sku=EK0469 
used to acquire anatomical images covering the whole brain [echo time $(\mathrm{TE})=2.52 \mathrm{~ms}$, repetition time $(\mathrm{TR})=1,900 \mathrm{~ms}$, inversion time $(\mathrm{TI})=900 \mathrm{~ms}$, flip angle $=9^{\circ}$, resolution matrix $=$ $256 \times 256$, slices $=176$, slice thickness $=1 \mathrm{~mm}$, voxel size $=$ $0.976 \times 0.976 \times 1 \mathrm{~mm}$, duration $=7: 49 \mathrm{~min}]$. All images were collected during a single imaging session. Whole brain voxelbased morphometry (VBM) (72) analysis was carried out on the T1-weighted images using the Diffeomorphic Anatomical Registration Through Exponentiated Lie Algebra (DARTEL) segmentation algorithm (73) as implied in SPM12. Image intensity inhomogeneity correction (bias-field correction) was achieved using SPM bias correction algorithm implemented in SPM segment (72). Reorientation of the images was fixed to the anterior commissure. The automatic detection of different tissue types within the T1-weighted images was archived using the standard segmentation model in SPM (72). The resulting gray matter ribbon was used for achieving accurate intersubject alignment using DARTEL (73). After the iterative alignment process (74), DARTEL generated flow field images as well as the DARTEL template. The resulting flow field maps and the DARTEL template were used to create the smoothed [6-mm full width at half maximum (FWHM)], Jacobian scaled, spatially normalized gray matter images into the Montreal Neurological Institute (MNI) coordinate system through nonlinear transformation $(74,75)$ before calculation of GMV and group comparison. With this choice of parameters, an affine transformation leads to a correction for differences in whole-brain volumes. Hence, our approach picks up relative regional, not absolute, brain volumes.

\section{Correlation Between Gray Matter Volume and Nerve Growth Factor Serum Levels}

Whole-brain correlation analysis between NGF serum levels and GMV were performed for schizophrenia patients and healthy controls separately, as well as a combined group of patients and controls to identify disease-specific associations between NGF and GMV. The main analyses were performed including voxel-wise GMV values as the dependent variable and NGF serum levels as a predictor. Group status was included as an additional regressor in the general sample (i.e., patients and healthy controls combined).

For all tests general linear model (GLM) was used to determine the statistical inference. The cluster level multiple comparison correction was performed to delineate the significant clusters (at $\mathrm{p}<.001$, uncorrected). To focus all subsequent analyses on clusters of biological meaning, we chose a cluster extent threshold of $\mathrm{k}>100$ voxels. As brain structural changes after disease onset show a regional pattern, we purposefully chose this approach that is especially prone to pick up these changes.

\section{Overlap of Correlation Analysis and Group Comparison}

To identify possible overlaps between clusters correlated to NGF levels and GMV differences, a conjunction analysis was conducted.

First, to achieve a whole brain voxel-wise group GMV comparison between patients and controls, GLM analysis was performed using a two-sample t-test $(\mathrm{p}<.001)$ to identify core structural gray matter differences in schizophrenia patients.
Cluster-level threshold was set at $\mathrm{p}<.05$ using family-wise error correction (FWE) with a voxel-level threshold set at $\mathrm{p}<.001$. To focus all subsequent analyses on clusters of biological meaning, we chose a cluster extent threshold of $\mathrm{k}>100$ voxels.

To objectify a potential anatomical overlap, we computed a conjunction analysis between the results of the group comparison (schizophrenia patients and healthy controls) and the findings of our correlation analyses (correlation between serum NGF levels and GMV). That is, by computing the intersection of the thresholded maps from the group comparison and the correlation analyses (76), we aimed to investigate an overlap between structural changes associated with schizophrenia and GMVs correlated with NGF.

\section{Anatomical Labeling}

We used the SPM Anatomy Toolbox 2.2c (77-79) to obtain an anatomical localization of the resulted clusters from the group comparisons as well as the correlation analyses. The Anatomy Toolbox provides two different sets of information for a given cluster: a cortical area and a probabilistic microanatomical allocation based on cytoarchitectural probabilistic mapping (77-79). Wherever obtainable, we report both the macro- and the microanatomical labels. In all other cases, we report the macroanatomical allocations as provided by the Anatomy Toolbox.

\section{Functional Decoding}

To obtain an observer-independent data-driven functional characterization of the clusters ensuing from our VBM analyses, we assessed whether we could find significant associations with behavioral domains and paradigm classes provided by the BrainMap data base (http://www.brainmap.org) (80, 81), a data base of published functional neuroimaging experiments. Here, behavioral domains describe the mental process likely to be isolated by an experimental contrast. They are divided into main categories: action, cognition, emotion, interception and perception, and their related subcategories. Furthermore, paradigm classes representing specific and established tasks of the experiments were used to determine activation in defined brain regions (for a detailed BrainMap taxonomy, see http://www.brainmap.org/taxonomy). Since it was our aim to characterize the physiological function of the identified brain regions, we only referred to studies on healthy subjects. Forward and reverse inference was performed. The forward inference approach denotes the probability of a particular mental process activating a specific brain region [ $\mathrm{P}$ (activation|task)] in comparison to the probability of (random) activation in this specific brain region at baseline $[\mathrm{P}($ activation $)]$. In the interest of clarity, results for forward and reverse inference are displayed in one column. Significance was assessed using a binominal test $(\mathrm{p}<.05)$, corrected for multiple comparisons using false discovery rate (FDR). The reverse inference approach attempts to identify the most likely psychological process, described in the categories of behavioral domains and paradigm classes, being implemented given neural activation in a specific brain region or network $[\mathrm{P}($ task|activation $)]$. Significance was assessed here using a chi-square test $(\mathrm{p}<.05)$, FDR-corrected. 


\section{RESULTS}

\section{Correlation of Clinical Data and Gray Matter Volume With Nerve Growth Factor Serum Levels}

In schizophrenia patients, serum NGF levels were found to be positively correlated with GMV in the pons (Table 2, TableS1, and Figure 1). The cluster was significantly associated with the paradigm class of pain monitoring and pain discrimination. Two clusters were negatively correlated between NGF serum levels and GMV, one cluster located in the left mid orbital gyrus extending into the right hemisphere, and the other in the left MCC (Table 2, Figure 1). Both clusters were found to be associated with reward related tasks.

We did not find any cluster to be significantly negatively or positively correlated with NGF in either the healthy control or the combined group.

NGF serum levels did not differ significantly between schizophrenia patients and healthy controls $(\mathrm{z}=-1.401, \mathrm{p}=.169)$. However, NGF levels tended to be reduced in schizophrenia patients. NGF was found to be symmetrically distributed in healthy controls $(\mathrm{p}=.076)$, however, not symmetrically distributed in patients $(\mathrm{p}=.007)$.

In our study sample, no significant correlation was found between BMI and NGF serum levels in patients, as well as in healthy controls (SZ: $\mathrm{r}_{\mathrm{s}}=0.251, \mathrm{p}=0.316$, HC: $\mathrm{r}_{\mathrm{s}}=-0.418, \mathrm{p}=$ 0.075). In schizophrenia patients, no significant correlation was found between daily olanzapine (equivalent) dose and NGF serum levels $\left(r_{s}=0.87, p=0.732\right)$. In our study sample, significant correlation was not found between sex, BMI, years of education, and pack-years nor between the amount of weekly physical exercise and NGF serum levels in patients as well as in healthy controls. No correlation between age and NGF in patients was found, however, in healthy controls ( $r s=-.507, \mathrm{p}=.027$ ). Years of education were significantly correlated to NGF serum levels in controls ( $\mathrm{rs}=-.697, \mathrm{p}=.001)$, but not in schizophrenia patients. In schizophrenia patients, no correlation between neither duration of disease, daily olanzapine (equivalent) dose, or neither the results of PANSS test (positive, negative, general, and total scale) and NGF serum levels were found.

TABLE 2 | Results of VBM analyses: Correlation analysis.

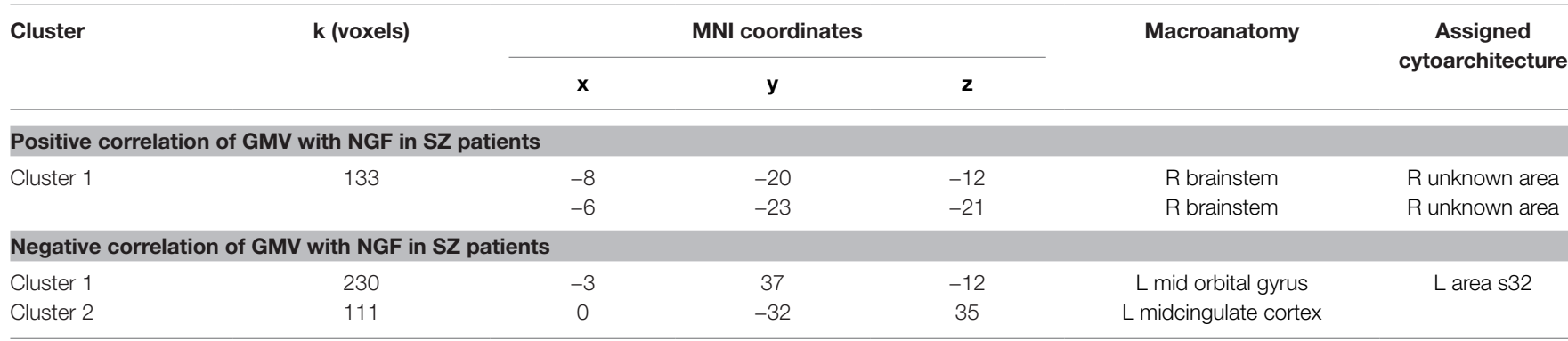

Whole-brain correlation analysis between NGF serum levels and GMV were performed to identify disease-specific associations between NGF and GMV. No cluster was found to be significantly negatively or positively correlated with NGF in either the healthy control or the combined group of patients and controls. NGF, nerve growth factor; GMV, gray matter volume. For detailed information on assigned probabilistic cytoarchitectonic areas, please refer to area s32 (82).

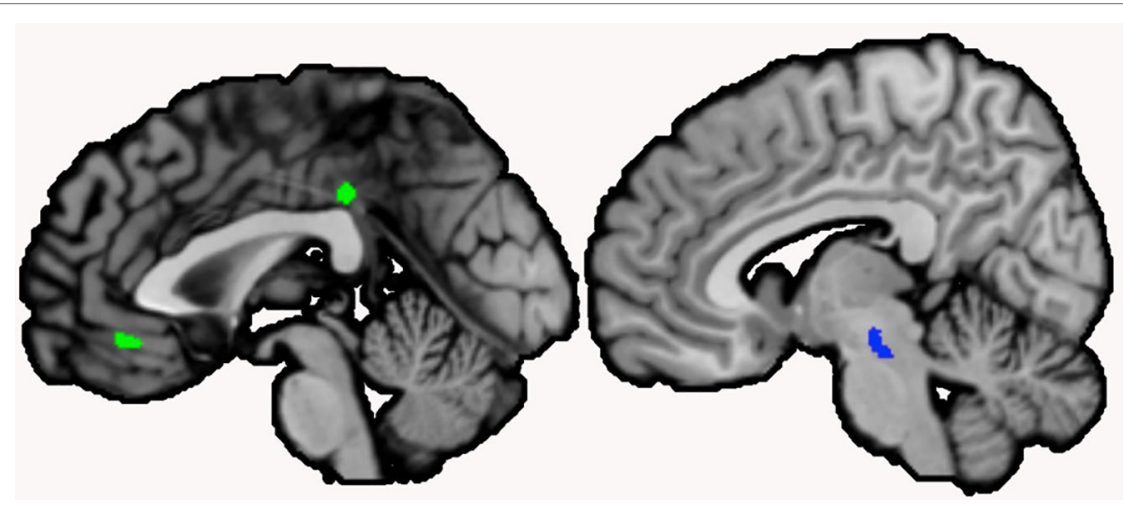

FIGURE 1 | Clusters correlated with serum nerve growth factor (NGF) in schizophrenia patients. Note: Clusters correlated with serum NGF levels in schizophrenia patients were located in the left midcingulate cortex (extending over the midline) and the left mid orbital gyrus (extending over the midline; negative correlation, shown in green), and the brainstem (positive correlation, shown in blue; sagittal view, $p<.001$, cluster-level threshold $p<.05$, FWE-corrected, $k>100$ ) 


\section{Group Comparison and Conjunction Analysis}

We found significant reduction of GMV in schizophrenia patients in 11 clusters. Clusters were located in the cingulate [left midcingulate cortex (MCC), right anterior cingulate cortex], bilaterally parietal lobes, bilateral insula, bilateral auditory cortex superior temporal lobe, left frontal lobe, and the bilateral occipital lobe (Table 3, Figure 2).

The clusters showing reduced GMV in schizophrenia patients were associated with social cognition, reasoning, action execution and language-related processes (see Table 5 for an overview).
We did not find any increase in GMV in schizophrenia patients compared to healthy controls.

Subsequent conjunction analysis revealed an overlap $(k=60)$ between the NGF serum level to GMV correlation and the GMV group comparison in the left MCC in schizophrenia patients.

\section{DISCUSSION}

In this study, we found evidence for a correlation between NGF serum levels and GMV in the left prefrontal lobe, the left MCC,

TABLE 3 | Results of VBM analyses: Clusters of reduced GMV in SZ patients.

\begin{tabular}{|c|c|c|c|c|c|c|}
\hline \multirow[t]{2}{*}{ Cluster } & \multirow[t]{2}{*}{ k (voxels) } & \multicolumn{3}{|c|}{ MNI coordinates } & \multirow[t]{2}{*}{ Macroanatomy } & \multirow{2}{*}{$\begin{array}{c}\text { Assigned } \\
\text { cytoarchitecture }\end{array}$} \\
\hline & & $\mathbf{x}$ & $\mathbf{y}$ & $\mathbf{z}$ & & \\
\hline \multirow[t]{5}{*}{ Cluster 1} & 2,618 & 5 & -77 & 15 & $\mathrm{R}$ calcarine gyrus & $\mathrm{R}$ area hOc2 (V2) \\
\hline & & -2 & -85 & 22 & L cuneus & $\mathrm{L}$ area hOc3d \\
\hline & & 2 & -85 & 20 & L cuneus & $\mathrm{L}$ area hOc2 (V2) \\
\hline & & -2 & -84 & 13 & L calcarine gyrus & $\mathrm{L}$ area hOc2 (V2) \\
\hline & & -1 & -85 & 14 & L calcarine gyrus & $\mathrm{L}$ area hOc2 (V2) \\
\hline Cluster 2 & 718 & 1 & -28 & 33 & L midcingulate cortex & \\
\hline \multirow[t]{5}{*}{ Cluster 3} & 580 & 7 & -65 & 31 & R precuneus & \\
\hline & & -4 & -57 & 35 & L precuneus & \\
\hline & & -3 & -59 & 33 & L precuneus & \\
\hline & & 3 & -62 & 31 & L precuneus & \\
\hline & & 1 & -61 & 32 & L precuneus & \\
\hline Cluster 4 & 371 & 4 & -90 & -6 & L calcarine gyrus & $\mathrm{L}$ area hOc1 (V1) \\
\hline Cluster 5 & 297 & -39 & 22 & 1 & L insula lobe & \\
\hline Cluster 6 & 264 & 53 & -8 & 4 & $\mathrm{R}$ heschls gyrus & $\mathrm{R}$ area TE 1.0 \\
\hline Cluster 7 & 257 & 37 & 25 & 2 & $R$ insula lobe & \\
\hline Cluster 8 & 256 & 4 & 18 & 25 & $\mathrm{R}$ anterior cingulate cortex & $\mathrm{R}$ area 33 \\
\hline \multirow[t]{3}{*}{ Cluster 9} & 246 & -44 & -1 & 0 & Left Rolandic operculum & \\
\hline & & -43 & -6 & 1 & Left insula lobe & \\
\hline & & -48 & 1 & 0 & Left superior temporal gyrus & \\
\hline Cluster 10 & 241 & 0 & 4 & 48 & Left post.-med. frontal gyrus & \\
\hline Cluster 11 & 149 & -54 & -9 & 4 & Left superior temporal gyrus & $\mathrm{L}$ area TE 1.2 \\
\hline
\end{tabular}

L, left; R, right, V1, visual area 1; V2, visual area 2; Post.-Med., posterior-medial. For detailed information on assigned probabilistic cytoarchitectonic areas, please refer to area hOc1 and area hOc2 (83); area hOc3a (84); area TE 1.0 and area TE 1.2 (85, 86); area 33 (82).
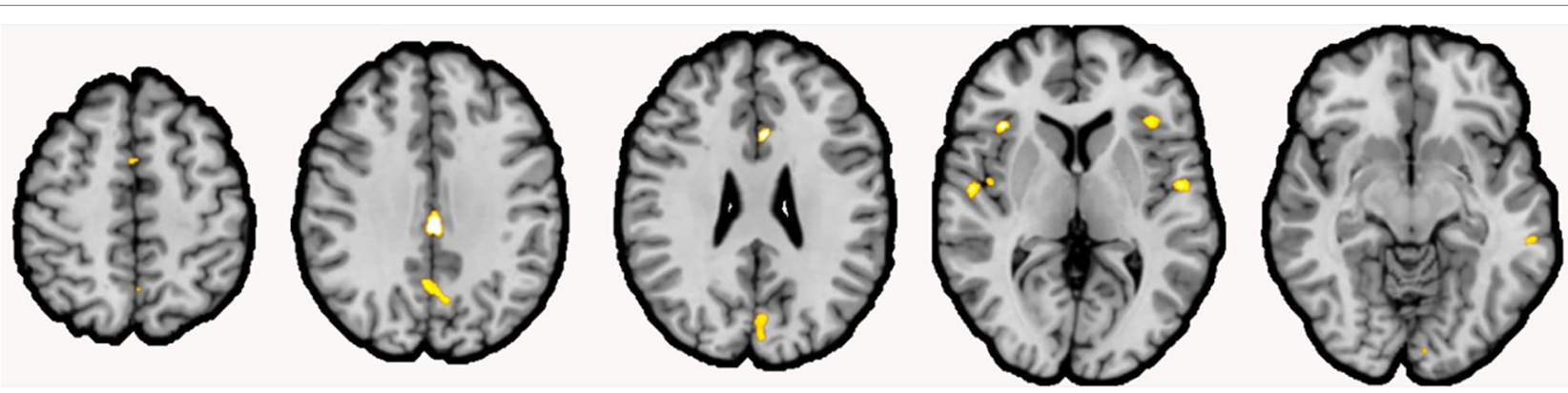

FIGURE 2 | Gray matter volume (GMV) reductions in schizophrenia patients compared to healthy controls. Note: Clusters of reduced GMV in schizophrenia patients (shown in yellow) compared to healthy controls were located inter alia the bilateral insula, the left Rolandic operculum, the left area TE 1.2 and the right area TE 1.0, the right anterior cingulate cortex (ACC; extending over the midline), left posterior-medial frontal gyrus, the left midcingulate cortex (MCC; extending over the midline), the right precuneus (extending over the midline), and the visual areas hOc1 and hOc2 (both extending over the midline; coronal view, $p<.001$, cluster-level threshold $p<.05$, FWE-corrected, $k>100)$. 
TABLE 4 | Results of VBM analyses: Conjunction analysis.

\begin{tabular}{|c|c|c|c|c|c|c|}
\hline \multirow[t]{2}{*}{ Cluster } & \multirow[t]{2}{*}{ k (voxels) } & \multicolumn{3}{|c|}{ MNI coordinates } & \multirow[t]{2}{*}{ Macroanatomy } & \multirow{2}{*}{$\begin{array}{c}\text { Assigned } \\
\text { cytoarchitecture }\end{array}$} \\
\hline & & $\mathbf{x}$ & $\mathbf{y}$ & $\mathbf{z}$ & & \\
\hline Cluster 1 & 60 & 0 & -31 & 34 & L midcingulate cortex & \\
\hline
\end{tabular}

Conjunction analysis revealed an overlap between the NGF serum level to GMV correlation and the GMV group comparison in the left MCC in schizophrenia patients. L, left.

TABLE 5 | Functional characterization for results of group difference and correlation analyses.

\begin{tabular}{|c|c|c|c|}
\hline Cluster & Region & $\begin{array}{l}\text { Behavioral domain } \\
\text { Mental process }\end{array}$ & $\begin{array}{l}\text { Paradigm class } \\
\text { Experimental task }\end{array}$ \\
\hline \multicolumn{4}{|c|}{ Positive correlation of GMV with NGF in SZ patients } \\
\hline Cluster 1 & Brainstem & No significant effects. & Pain monitor/discrimination \\
\hline \multicolumn{4}{|c|}{ Negative correlation of GMV with NGF in SZ patients } \\
\hline Cluster 1 & Area s32 & $\begin{array}{l}\text { Emotion } \\
\text { Cognition }\end{array}$ & Reward \\
\hline Cluster 2 & L MCC & $\begin{array}{l}\text { Emotion } \\
\text { Cognition }\end{array}$ & Reward \\
\hline \multicolumn{4}{|c|}{ Clusters of reduced GMV in SZ patients } \\
\hline Cluster 1 & Area hOc2 (V2) & $\begin{array}{l}\text { Perception. vision. } \\
\text { Perception. vision. motion }\end{array}$ & Saccades \\
\hline Cluster 2 & L MCC & $\begin{array}{l}\text { Action. inhibition } \\
\text { Cognition } \\
\text { Social cognition } \\
\text { Emotion }\end{array}$ & Reward, go/no-go \\
\hline Cluster 3 & R precuneus & $\begin{array}{l}\text { Cognition. social cognition } \\
\text { Cognition. reasoning }\end{array}$ & Self-reflection, theory of mind \\
\hline Cluster 4 & Area hOc1 (V1) & No significant effects. & No significant effects. \\
\hline Cluster 5 & L insula & $\begin{array}{l}\text { Cognition. language. semantics } \\
\text { Cognition. language. speech }\end{array}$ & $\begin{array}{l}\text { Word generation (covert) } \\
\text { Recitation/repetition (overt) }\end{array}$ \\
\hline Cluster 6 & Area TE 1.0 & No significant effects. & No significant effects. \\
\hline Cluster 7 & $R$ insula & Action. execution. speech & $\begin{array}{l}\text { Delayed match to sample } \\
\text { Recitation/repetition (overt) }\end{array}$ \\
\hline Cluster 8 & $\mathrm{R}$ ACC & Perception. somesthesis. pain & No significant effects. \\
\hline Cluster 9 & L Rolandic operculum & No significant effects. & No significant effects. \\
\hline Cluster 10 & Area TE 1.2 & No significant effects. & No significant effects. \\
\hline Cluster 11 & LPMF gyrus & $\begin{array}{l}\text { Perception. somesthesis } \\
\text { Perception. somesthesis. pain } \\
\text { Action. execution }\end{array}$ & $\begin{array}{l}\text { Grasping, saccades, visuospatial } \\
\text { attention, pain monitor/discrimination, } \\
\text { recitation/repetition (overt) }\end{array}$ \\
\hline
\end{tabular}

Functional characterization of the clusters retrieved from our main analyses. We used a data-driven approach to assign functional labels to clusters. In brief, this approach is based on BrainMap, a functional imaging data base, that provides functional annotations for given MNI coordinates (80, 81). We here report the functional labels that were assigned to the clusters from our main analyses above chance.

V1, visual area 1; V2, visual area 2; L, left; R, right; MCC, midcingulate cortex; ACC, anterior cingulate cortex; STL, superior temporal lobe, PMF gyrus, posterior-medial frontal gyrus.

and the brainstem in schizophrenia patients. To the best of our knowledge, this is the first study to investigate a putative influence of NGF levels on structural neuroanatomy in schizophrenia.

Remarkably, the GMV in the left MCC was reduced in our group comparison of schizophrenia patients and healthy controls and additionally was shown to be negatively correlated to NGF serum levels in schizophrenia patients, but not in healthy controls. A conjunction analysis identified an overlap between the results of the correlation and the group comparison analysis in the left MCC.

Reduction in cingulate gyrus volume has been found in several studies in schizophrenia patients. Significant reductions were found also in first-episode patients and were shown to be progressive in longitudinal examinations $(8,16,87)$. Finding the cingulate gyrus volume additionally correlated to NGF serum levels indicates an exceptional sensitivity for structural changes 


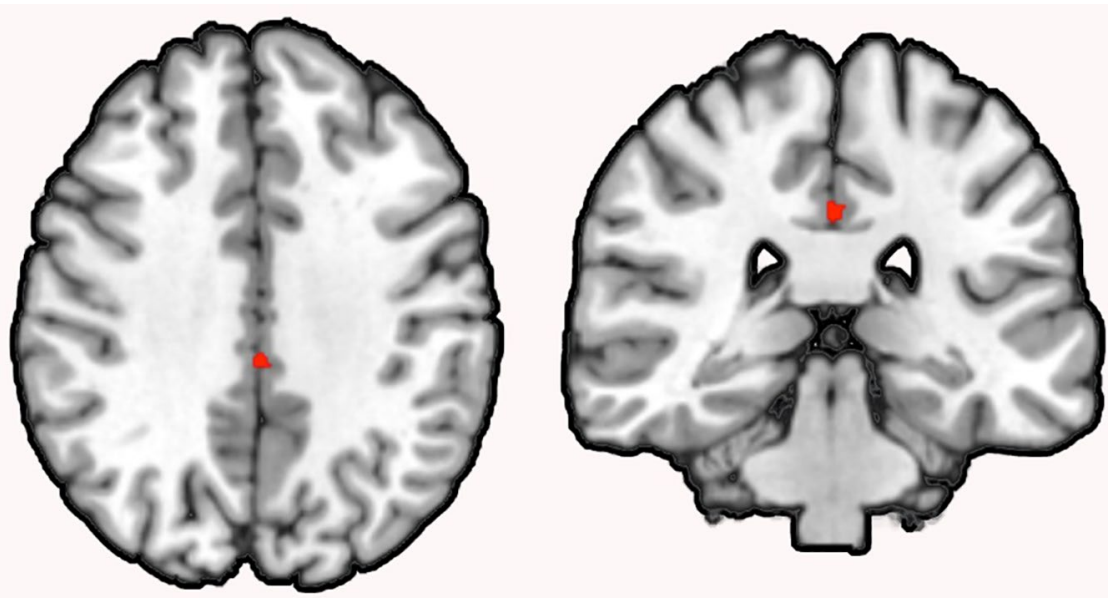

FIGURE 3 | Conjunction analysis of correlation and group comparison analysis. Note: Conjunction analysis revealed an overlap ( $k=60)$ between the NGF serum level to GMV correlation and the GMV group comparison in the left MCC in schizophrenia patients (coronal view, $p<.001$, cluster-level threshold $p<.05$, FWEcorrected, $k>60$ ).

and supports the hypothesis of NGF signaling playing a central role in the pathogenesis of brain structural differences in a core region of schizophrenia.

Also, the left orbital gyrus volume was found to be negatively correlated with serum NGF in the patient's group. Volume reductions in the orbital gyrus have been reported previously in schizophrenia patients $(17,88)$. In these studies, the volume of the left orbital gyrus was found inversely correlated with lower socioeconomic status and longer illness duration, suggesting a relation to social functioning impairment even during the firstepisode of schizophrenia $(88,89)$. Psychopathologically, reduced GMV in the left mid orbital gyrus has been associated with more severe positive formal thought disorders (88).

Both the MCC and orbital cortex play a decisive role in social interaction (90-93). NGF is also thought to play a mechanistic role in human social interaction $(94,95)$. In acute psychosocial stress, NGF in saliva was found elevated (96). Interestingly, subjects reporting lower negative emotion when confronting the stressor also showed greater NGF reactivity in saliva, suggesting that this neurotrophic response might have evolved as a resilience mechanism to protect the brain against the effects of stress hormones release. These findings suggest that both salivary NGF reactivity and recovery are markers of psychiatric health (96). A recent study reported an association between functional impairment and serum NGF levels in mental disorders. NGF levels were negatively associated with social and financial autonomy and cognition (97). Given the findings of our functional decoding, MCC and orbital cortex are plausible regions mediating these functions, as being associated with emotion, cognition as well as reward-related tasks. Finding a negative correlation between the GMV in the MCC and orbital cortex with NGF serum levels can indicate an increased vulnerability for neurostructural alternations, reflecting in difficulties in social interaction and functioning (98).

In schizophrenia patients, serum NGF levels were found to be positively correlated with GMV in the pons. Functional characterization has revealed that the pontine region is linked to tasks involving pain monitoring and pain discrimination. Abnormal pain sensitivity in schizophrenia was previously reported in clinical and experimental studies, showing that schizophrenia patients appear to have diminished pain perception (99-101).

NGF, as a key regulator of nociceptive pain and an important mediator of the initiation and maintenance of different pain stages $(102,103)$, has an important role in pain perception. NGF antagonists have been investigated in the treatment of nociceptive and neuropathic pain conditions (102-104). Thus, the pontine cluster that was positively correlated with NGF serum levels might be a neuroanatomical correlate of NGF-mediated altered pain sensitivity in schizophrenia patients. Finding a positive correlation of serum NGF to a neuroanatomical area involved in pain management may conversely suggest an influence of altered, more precisely in terms of reduced, NGF serum levels in diminished pain perception that can be observed in schizophrenia patients.

The observation that the correlations between NGF and brain structure were exclusively present in schizophrenia patients suggests an altered effect of NGF signaling in the brains of schizophrenia patients compared to controls. There is mounting evidence for this hypothesis $(50,58,70,105)$, hinting at NGF signaling acting via different mechanisms in schizophrenia. Changes due to altered signaling mechanisms might be intensified through per se decreased NGF levels in patients. Another possibility may be a dysfunctional NGF signaling cascade, e.g., because of a higher burden of genetic lesions in patients (56).

As NGF is mainly involved in the maintenance of neurons and neuronal circuits, a positive correlation between NGF serum levels and GMV would appear as most proximate hypothesis. Two aspects, however, challenge such a straightforward model. First, while NGF might indeed lead to decreased efficiency of neural networks, this does not have to manifest necessarily 
in brain atrophy detectable by MRI. Contrariwise, (failed) compensatory reactions might lead to increased regional GMV. Second, as the molecular architecture of the human brain arguably differs across regions (106), reactions of complex neural tissues toward reduced NGF levels do not necessarily have to be uniform across all brain regions. While these considerations might provide some explanation for detection of both positive and negative correlations between GMV and NGF levels across brain regions, we, though, have to acknowledge that such interpretations remain highly speculative. Future studies will have to corroborate these findings and follow up further on their mechanistic underpinnings.

In our cross-sectional comparison to healthy controls, we found a significant reduction of GMV in schizophrenia patients in the visual system, the limbic system, parietal lobe, bilateral insula, primary auditory cortex, and frontal lobe. Structural alterations particularly for fronto-temporal and limbic gray matter in schizophrenia patients have been described before $(5,8,17,26)$. Functional characterization revealed a prominent functional conjunction between clusters showing reductions in GMV with social cognition, reasoning, action execution, and language-related processes, which are domains related to core symptoms of schizophrenia (107-114). Previous study hints that some of these regions are related to severity of symptoms, so, for instance, there are indications that reduced GMV in the primary visual areas is associated with increased severity of visual hallucinations in schizophrenia patients (115).

Both BMI (69) as well as antipsychotics (24) have been shown to exert an influence on NGF serum levels, and have also been discussed as being correlated with brain structural changes (21, 116). For our sample, we did not find a correlation between these two parameters and NGF levels. Consequently, we would assume that our correlation analyses were not driven by these confounds. However, future studies on larger collectives will have to investigate these relationships further, to corroborate our findings.

\section{Nerve Growth Factor Pathways in Schizophrenia}

Neurotrophins, such as NGF, are known to pass the blood-brain barrier in both directions $(46,49)$. Kale et al. demonstrated a close relationship between CNS and peripheral NGF levels in healthy controls, but this correlation could not be found in drugnaive psychotic patients (50).

NGF is expressed throughout the cortex and of unique importance for maintenance and function of cholinergic neurons (117). The signaling pathways of NGF are still not fully understood. One pathway of survival, axonal growth, and differentiation of neural cells is mediated by NGF through binding to tropomyosine-related kinase (Trk)-receptor A (117, 118). NGF induces a calcium-dependent release of dopamine and glutamine (119) in a dose-dependent fashion (120) through a p75 neurotrophin receptor-dependent pathway $(120,121)$. Glutamate-gated ion channels as N-methyl-D-aspartate receptors (NMDARs) are widely distributed throughout the cortex (122), playing key roles in excitatory synaptic transmission and having a central role in synaptic plasticity (123).
There is a strong indication that NMDARs may play an important role in schizophrenia and psychosis $(123,124)$. Proven changes in the glutamatergic metabolism and transmission may potentially affect regional neuronal integrity and therefore be related to the morphological brain changes and symptoms in schizophrenia patients $(122,125)$. On the other hand, NMDA dysfunction may also affect the impaired dopaminergic and GABAergic neurotransmission documented in schizophrenia (122). NMDA and dopamine dysfunction are widely recognized to play a central role in disturbed neurotransmission of schizophrenia patients (126).

Different mechanisms in NGF signaling cascade, moreover enhanced through changes in NGF levels, may thereby lead to a less support on a trophic level and may in consequence contribute to changes in brain morphology $(117,127)$.

\section{Limitations}

The presented study follows an exploratory approach and the results of this study should be interpreted in the context of certain limitations. Although NGF levels have shown to be stable in peripheral blood (128), a single measurement of NGF serum levels cannot reflect the influence of NGF on long-term brain structural changes.

Moreover, NGF levels in peripheral blood only partially reflect actual level and activities of NGF in the CNS, since NGF is mainly produced in the CNS, but also produced, stored, and released in several immune cells like monocytes and lymphocytes (129) and platelets (130-134). Recent evidence points to a sufficient correlation between peripheral and central nervous NGF levels, whereas this correlation was only shown in healthy controls but not in schizophrenia patients (51). A disturbed blood-brain barrier in schizophrenia patients is discussed to contribute to the development of neuromorphological changes, maybe thereby provoking the raising of NGF autoantibodies (59). However, intensified research on NGF as a proxy marker for NGF in brain tissue is needed.

Although our study showed no correlation between NGF serum level and olanzapine equivalent, NGF level has been shown to be affected by medication in other studies, predominantly by adjusting the NGF serum level to levels of healthy subjects (24, 135-140).

NGF serum levels were not symmetrically distributed in schizophrenia patients. While the small sample size did not allow to follow up on potential subgroups, this will be an important issue for future studies.

Several aspects support the actual biological relevance of our findings: first, a variety of potentially relevant covariates did not show significant correlations with NGF serum levels in the general sample or in any of the subgroups. Only for the healthy controls, we found significant correlations of NGF serum levels with age and years of education. Both covariates might have an influence on brain structure. However, it should be noted that significant correlations between NGF serum levels and brain structure were found only for schizophrenia patients and not in healthy controls. Second, none of the analyzed covariates were significantly correlated with NGF serum levels in schizophrenia 
patients. We would regard this as an argument that our findings were indeed associated with NGF serum levels and not driven by another covariate. Third, the affine transformation of our analysis approach will correct for overall brain volume. This should also help to correct for effects associated with age and gender. While the use of more covariates should help to further correct against biases in larger samples, we would regard these aspects as good indicators that the results reported in this pilot study were not mainly driven by covariates.

The comparatively small sample size is certainly an important limitation of our exploratory pilot study. While we certainly would like to caution the reader regarding premature conclusions drawn from our findings, we would see our results as an encouraging lead toward a relationship between NGF levels and brain structural changes in schizophrenia, and a strong urge for future studies enrolling larger samples. A larger sample size may consider covariates like sex, age, medication, or illness duration in a more solid way. Finally, a larger sample size may uncover more subtle alterations in the brain structure of schizophrenia patients and decrease the danger of false positive findings. As a follow-up to our study, analysis of the precursor protein of NGF and the interaction between the precursor and the mature form might indicate other signaling pathways and effects (117). Extension of the study concept by DTI analysis of white matter as well as functional imaging via fMRI may be of great interest. Moreover, a longitudinal study may be desirable to investigate the potential effect of NGF on brain structure changes in temporal course. Delineating the effects of NGF levels on early brain development would be desirable in individuals that later present with schizophrenia. Such a correlation could be investigated, e.g., in larger longitudinal cohorts of at-risk individual at younger ages.

\section{Conclusion}

Our pilot study offered hints about the influence of serum NGF on the brain structure of several regions in schizophrenia patients, while no comparable results had been found in healthy controls. Remarkably, changes correlated with NGF serum levels manifested also in the cingulate cortex, a region that also showed volume reductions our group comparison between patients and controls and has been repeatedly implicated in the literature as morphologically altered in schizophrenia. While our sample

\section{REFERENCES}

1. Honea R, Crow TJ, Passingham D, Mackay CE. Regional deficits in brain volume in schizophrenia: a meta-analysis of voxel-based morphometry studies. Am J Psychiatry (2005) 162:2233-45. doi: 10.1176/appi.ajp.162. 12.2233

2. Bora E, Fornito A, Radua J, Walterfang M, Seal M, Wood SJ, et al. Neuroanatomical abnormalities in schizophrenia: a multimodal voxelwise meta-analysis and meta-regression analysis. Schizophr Res (2011) 127:46-57. doi: 10.1016/j.schres.2010.12.020

3. Nickl-Jockschat T, Schneider F, Pagel AD, Laird AR, Fox PT, Eickhoff SB. Progressive pathology is functionally linked to the domains of language and emotion: meta-analysis of brain structure changes in schizophrenia patients. certainly was small, we regard these findings as an encouraging indication for further research. The recruitment of larger samples will be an important goal for future studies.

\section{ETHICS STATEMENT}

The study protocol was approved by the local ethics committee of the RWTH Aachen University. Before being enrolled in the study, written informed consent was obtained from each subject in accordance with the Declaration of Helsinki.

\section{AUTHOR CONTRIBUTIONS}

TN-J contributed to the conception and design of the study, and supervised data acquisition, analysis, and interpretation, as well as manuscript proofreading. LM, MS, and AN conducted informed consent. WG arranged MRI settings. KN, TW, and VK performed analysis of the MRI data. KN contributed to data acquisition, analysis, interpretation, and wrote the manuscript. $\mathrm{CH}$ contributed to data acquisition. TW, TA, WG, and $\mathrm{UH}$ contributed to manuscript proofreading.

\section{FUNDING}

This work was sponsored by the foundation program "START" of the Ministry of Science and Research of the state of North RhineWestphalia, Germany.

\section{ACKNOWLEDGMENTS}

We thank J. Weis for his contribution to the application for the START foundation. The authors thank all the investigational sites for their participation in this study.

\section{SUPPLEMENTARY MATERIAL}

The Supplementary Material for this article can be found online at: https:/www.frontiersin.org/articles/10.3389/fpsyt.2019.00275/ full\#supplementary-material

Eur Arch Psychiatry Clin Neurosci (2011) 261 Suppl 2:S166-171. doi: 10.1007/ s00406-011-0249-8

4. Olabi B, Ellison-Wright I, Mcintosh AM, Wood SJ, Bullmore E, Lawrie SM. Are there progressive brain changes in schizophrenia? A meta-analysis of structural magnetic resonance imaging studies. Biol Psychiatry (2011) 70:8896. doi: 10.1016/j.biopsych.2011.01.032

5. Shepherd AM, Laurens KR, Matheson SL, Carr VJ, Green MJ. Systematic meta-review and quality assessment of the structural brain alterations in schizophrenia. Neurosci Biobehav Rev (2012) 36:1342-56. doi: 10.1016/j. neubiorev.2011.12.015

6. Vita A, De Peri L, Deste G, Sacchetti E. Progressive loss of cortical gray matter in schizophrenia: a meta-analysis and meta-regression of longitudinal MRI studies. Transl Psychiatry (2012) 2:e190. doi: 10.1038/tp.2012.116 
7. Gupta CN, Calhoun VD, Rachakonda S, Chen J, Patel V, Liu J, et al. Patterns of gray matter abnormalities in schizophrenia based on an international mega-analysis. Schizophr Bull (2015) 41:1133-42. doi: 10.1093/schbul/ sbu177

8. Nemoto K. Voxel-based morphometry for schizophrenia: a review. Brain Nerve (2017) 69:513-8. doi: 10.11477/mf.1416200777

9. Stephan KE, Baldeweg T, Friston KJ. Synaptic plasticity and dysconnection in schizophrenia. Biol Psychiatry (2006) 59:929-39. doi: 10.1016/j.biopsych. 2005.10.005

10. Rapoport JL, Giedd JN, Gogtay N. Neurodevelopmental model of schizophrenia: update 2012. Mol Psychiatry (2012) 17:1228-38. doi: 10.1038/ mp.2012.23

11. Pang L, Kennedy D, Wei Q, Lv L, Gao J, Li H, et al. Decreased functional connectivity of insular cortex in drug naive first episode schizophrenia: in relation to symptom severity. PLoS One (2017) 12:e0167242. doi: 10.1371/ journal.pone.0167242

12. Yue Y, Kong L, Wang J, Li C, Tan L, Su H, et al. Regional abnormality of grey matter in schizophrenia: effect from the illness or treatment? PLoS One (2016) 11:e0147204. doi: 10.1371/journal.pone.0147204

13. Kim GW, Kim YH, Jeong GW. Whole brain volume changes and its correlation with clinical symptom severity in patients with schizophrenia: A DARTEL-based VBM study. PLoS One (2017) 12:e0177251. doi: 10.1371/ journal.pone.0177251

14. Ellison-Wright I, Glahn DC, Laird AR, Thelen SM, Bullmore E. The anatomy of first-episode and chronic schizophrenia: an anatomical likelihood estimation meta-analysis. Am J Psychiatry (2008) 165:1015-23. doi: 10.1176/ appi.ajp.2008.07101562

15. Leung M, Cheung C, Yu K, Yip B, Sham P, Li Q, et al. Gray matter in firstepisode schizophrenia before and after antipsychotic drug treatment. Anatomical likelihood estimation meta-analyses with sample size weighting. Schizophr Bull (2011) 37:199-211. doi: 10.1093/schbul/sbp099

16. Asami T, Bouix S, Whitford TJ, Shenton ME, Salisbury DF, Mccarley RW. Longitudinal loss of gray matter volume in patients with first-episode schizophrenia: DARTEL automated analysis and ROI validation. Neuroimage (2012) 59:986-96. doi: 10.1016/j.neuroimage.2011.08.066

17. Torres US, Duran FL, Schaufelberger MS, Crippa JA, Louza MR, Sallet PC, et al. Patterns of regional gray matter loss at different stages of schizophrenia: a multisite, cross-sectional VBM study in first-episode and chronic illness. Neuroimage Clin (2016) 12:1-15. doi: 10.1016/j.nicl.2016.06.002

18. Zhang C, Wang Q, Ni P, Deng W, Li Y, Zhao L, et al. Differential cortical gray matter deficits in adolescent- and adult-onset first-episode treatmentnaive patients with schizophrenia. Sci Rep (2017) 7:10267. doi: 10.1038/ s41598-017-10688-1

19. Meisenzahl EM, Koutsouleris N, Bottlender R, Scheuerecker J, Jager M, Teipel SJ, et al. Structural brain alterations at different stages of schizophrenia: a voxel-based morphometric study. Schizophr Res (2008) 104:44-60. doi: 10.1016/j.schres.2008.06.023

20. Kempton MJ, Stahl D, Williams SC, Delisi LE. Progressive lateral ventricular enlargement in schizophrenia: a meta-analysis of longitudinal MRI studies. Schizophr Res (2010) 120:54-62. doi: 10.1016/j. schres.2010.03.036

21. Ho BC, Andreasen NC, Ziebell S, Pierson R, Magnotta V. Long-term antipsychotic treatment and brain volumes: a longitudinal study of firstepisode schizophrenia. Arch Gen Psychiatry (2011) 68:128-37. doi: 10.1001/ archgenpsychiatry.2010.199

22. Cobia DJ, Smith MJ, Wang L, Csernansky JG. Longitudinal progression of frontal and temporal lobe changes in schizophrenia. Schizophr Res (2012) 139:1-6. doi: 10.1016/j.schres.2012.05.002

23. Haijma SV, Van Haren N, Cahn W, Koolschijn PC, Hulshoff Pol HE, Kahn RS. Brain volumes in schizophrenia: a meta-analysis in over 18000 subjects. Schizophr Bull (2013) 39:1129-38. doi: 10.1093/schbul/sbs118

24. Ajami A, Hosseini SH, Taghipour M, Khalilian A. Changes in serum levels of brain derived neurotrophic factor and nerve growth factor-beta in schizophrenic patients before and after treatment. Scand J Immunol (2014) 80:36-42. doi: 10.1111/sji.12158

25. Yeganeh-Doost P, Gruber O, Falkai P, Schmitt A. The role of the cerebellum in schizophrenia: from cognition to molecular pathways. Clinics (Sao Paulo) (2011) 66 Suppl 1:71-7. doi: 10.1590/\$1807-59322011001300009
26. Singh S, Modi S, Goyal S, Kaur P, Singh N, Bhatia T, et al. Functional and structural abnormalities associated with empathy in patients with schizophrenia: an fMRI and VBM study. J Biosci (2015) 40:355-64. doi: 10.1007/s12038-015-9509-5

27. Lu X, Yang Y, Wu F, Gao M, Xu Y, Zhang Y, et al. Discriminative analysis of schizophrenia using support vector machine and recursive feature elimination on structural MRI images. Medicine (Baltimore) (2016) 95:e3973. doi: 10.1097/MD.0000000000003973

28. Ho BC, Andreasen NC, Nopoulos P, Arndt S, Magnotta V, Flaum M. Progressive structural brain abnormalities and their relationship to clinical outcome: a longitudinal magnetic resonance imaging study early in schizophrenia. Arch Gen Psychiatry (2003) 60:585-94. doi: 10.1001/ archpsyc.60.6.585

29. Selemon LD, Goldman-Rakic PS. The reduced neuropil hypothesis: a circuit based model of schizophrenia. Biol Psychiatry (1999) 45:17-25. doi: 10.1016/ S0006-3223(98)00281-9

30. Black JE, Kodish IM, Grossman AW, Klintsova AY, Orlovskaya D, Vostrikov $\mathrm{V}$, et al. Pathology of layer $\mathrm{V}$ pyramidal neurons in the prefrontal cortex of patients with schizophrenia. Am J Psychiatry (2004) 161:742-4. doi: 10.1176/ appi.ajp.161.4.742

31. Chance SA, Casanova MF, Switala AE, Crow TJ. Auditory cortex asymmetry, altered minicolumn spacing and absence of ageing effects in schizophrenia. Brain (2008) 131:3178-92. doi: 10.1093/brain/awn211

32. Sweet RA, Henteleff RA, Zhang W, Sampson AR, Lewis DA. Reduced dendritic spine density in auditory cortex of subjects with schizophrenia. Neuropsychopharmacology (2009) 34:374-89. doi: 10.1038/npp.2008.67

33. Balu DT, Coyle JT. Neuroplasticity signaling pathways linked to the pathophysiology of schizophrenia. Neurosci Biobehav Rev (2011) 35:848-70. doi: 10.1016/j.neubiorev.2010.10.005

34. Glantz LA, Lewis DA. Decreased dendritic spine density on prefrontal cortical pyramidal neurons in schizophrenia. Arch Gen Psychiatry (2000) 57:65-73. doi: 10.1001/archpsyc.57.1.65

35. Bennett MR. Schizophrenia: susceptibility genes, dendritic-spine pathology and gray matter loss. Prog Neurobiol (2011) 95:275-300. doi: 10.1016/j. pneurobio.2011.08.003

36. Somenarain L. Disorders neuropathology of the prefrontal cortex neuropil in schizophrenia. Psychiatric (Trends and Development) (2011) 1-17. doi: $10.5772 / 25564$

37. Kahn RS, Sommer IE. The neurobiology and treatment of first-episode schizophrenia. Mol Psychiatry (2015) 20:84-97. doi: 10.1038/mp.2014.66

38. McAllister AK, Katz LC, Lo DC. Neurotrophins and synaptic plasticity. Annu Rev Neurosci (1999) 22:295-318. doi: 10.1146/annurev.neuro.22.1.295

39. Schinder AF, Poo M. The neurotrophin hypothesis for synaptic plasticity. Trends Neurosci (2000) 23:639-45. doi: 10.1016/S0166-2236(00)01672-6

40. Martinez-Cengotitabengoa M, Macdowell KS, Alberich S, Diaz FJ, GarciaBueno B, Rodriguez-Jimenez R, et al. BDNF and NGF signalling in early phases of psychosis: relationship with inflammation and response to antipsychotics after 1 year. Schizophr Bull (2016) 42:142-51. doi: 10.1093/schbul/sbv078

41. Large TH, Bodary SC, Clegg DO, Weskamp G, Otten U, Reichardt LF. Nerve growth factor gene expression in the developing rat brain. Science (1986) 234:352-5. doi: 10.1126/science.3764415

42. Levi-Montalcini R. The nerve growth factor 35 years later. Science (1987) 237:1154-62. doi: 10.1126/science.3306916

43. Weinberger D. Cell biology of the hippocampal formation in schizophrenia. Biol Psychiatry (1999) 45:395-402. doi: 10.1016/S0006-3223(98)00331-X

44. Cirulli F. Role of environmental factors on brain development and nerve growth factor expression. Physiol Behav (2001) 73:321-30. doi: 10.1016/ S0031-9384(01)00456-5

45. Oliveira SL, Pillat MM, Cheffer A, Lameu C, Schwindt TT, Ulrich H. Functions of neurotrophins and growth factors in neurogenesis and brain repair. Cytometry A (2013) 83:76-89. doi: 10.1002/cyto.a.22161

46. Poduslo JF, Curran GL. Permeability at the blood-brain and blood-nerve barriers of the neurotrophic factors: NGF, CNTF, NT-3, BDNF. Brain Res Mol Brain Res (1996) 36:280-6. doi: 10.1016/0169-328X(95)00250-V

47. Zhuo C, Ma X, Qu H, Wang L, Jia F, Wang C. Schizophrenia patients demonstrate both inter-voxel level and intra-voxel level white matter alterations. PLoS One (2016) 11:e0162656. doi: 10.1371/journal.pone. 0162656 
48. Poduslo JF, Curran GL, Berg CT. Macromolecular permeability across the blood-nerve and blood-brain barriers. Proc Natl Acad Sci U S A (1994) 91:5705-9. doi: 10.1073/pnas.91.12.5705

49. Pan W, Banks WA, Kastin AJ. Permeability of the blood-brain barrier to neurotrophins. Brain Res (1998) 788:87-94. doi: 10.1016/S0006-8993 (97)01525-4

50. Kale A, Joshi S, Pillai A, Naphade N, Raju M, Nasrallah H, et al. Reduced cerebrospinal fluid and plasma nerve growth factor in drug-naive psychotic patients. Schizophr Res (2009) 115:209-14. doi: 10.1016/j.schres.2009.07.022

51. Xiong P, Zeng Y, Zhu Z, Tan D, Xu F, Lu J, et al. Reduced NGF serum levels and abnormal P300 event-related potential in first episode schizophrenia. Schizophr Res (2010) 119:34-9. doi: 10.1016/j.schres.2010.02.1063

52. Lang UE, Jockers-Scherübl MC, Hellweg R. State of the art of the neurotrophin hypothesis in psychiatric disorders: implications and limitations. J Neural Transm (2004) 111:387-411. doi: 10.1007/s00702-003-0100-0

53. Shoval G, Weizman A. The possible role of neurotrophins in the pathogenesis and therapy of schizophrenia. Eur Neuropsychopharmacol (2005) 15:319-29. doi: 10.1016/j.euroneuro.2004.12.005

54. Qin XY, Wu HT, Cao C, Loh YP, Cheng Y. A meta-analysis of peripheral blood nerve growth factor levels in patients with schizophrenia. Mol Psychiatry (2017) 22:1306-12. doi: 10.1038/mp.2016.235

55. Rao S, Martinez-Cengotitabengoa M, Yao Y, Guo Z, Xu Q, Li S, et al. Peripheral blood nerve growth factor levels in major psychiatric disorders. J Psychiatr Res (2017) 86:39-45. doi: 10.1016/j.jpsychires.2016.11.012

56. Zakharyan R, Atshemyan S, Gevorgyan A, Boyajyan A. Nerve growth factor and its receptor in schizophrenia. BBA Clin (2014) 1:24-9. doi: 10.1016/j. bbacli.2014.05.001

57. Klyushnik TP, Danilovskaya EV, Vatolkina OE, Turkova IL, Tsutsul'kovskaya MY, Orlova VA, et al. Changes in serum levels of autoantibody to nerve growth factor in patients with schizophrenia. Neurosci Behav Physiol (1999) 29:355-7. doi: 10.1007/BF02465349

58. Shcherbakova IV, Efanova NN, Orlova VA, Kliushnik TP, Voskresenskaia NI, Gubskii AV, et al. MRI-parameters of frontal lobes in schizophrenia: correlations with the level of autoantibodies to nerve growth factor in the blood serum. Zh Nevrol Psikhiatr Im S S Korsakova (2009) 109:44-6.

59. Lang UE, Hellweg R, Sander T, Gallinat J. The Met allele of the BDNF Val66Met polymorphism is associated with increased BDNF serum concentrations. Mol Psychiatry (2009) 14:120-2. doi: 10.1038/mp.2008.80

60. Ho BC, Andreasen NC, Dawson JD, Wassink TH. Association between brain-derived neurotrophic factor Val66Met gene polymorphism and progressive brain volume changes in schizophrenia. Am J Psychiatry (2007) 164:1890-9. doi: 10.1176/appi.ajp.2007.05111903

61. Erickson KI, Prakash RS, Voss MW, Chaddock L, Heo S, Mclaren M, et al. Brain-derived neurotrophic factor is associated with age-related decline in hippocampal volume. J Neurosci (2010) 30:5368-75. doi: 10.1523/ JNEUROSCI.6251-09.2010

62. Kalinowska-Lyszczarz A, Pawlak MA, Wyciszkiewicz A, Pawlak-Bus K, Leszczynski P, Puszczewicz M, et al. Immune cell neurotrophin production is associated with subcortical brain atrophy in neuropsychiatric systemic lupus erythematosus patients. Neuroimmunomodulation (2017) 24:320-30. doi: $10.1159 / 000487139$

63. Kay SR, Fiszbein A, Opler LA. The Positive and Negative Syndrome Scale (PANSS) for schizophrenia. Schizophr Bull (1987) 13:261-76. doi: 10.1093/ schbul/13.2.261

64. Duman RS. Neurotrophic factors and regulation of mood: role of exercise, diet and metabolism. Neurobiol Aging (2005) 26 Suppl 1:88-93. doi: 10.1016/j.neurobiolaging.2005.08.018

65. Lommatzsch M, Zingler D, Schuhbaeck K, Schloetcke K, Zingler C, SchuffWerner $P$, et al. The impact of age, weight and gender on BDNF levels in human platelets and plasma. Neurobiol Aging (2005) 26:115-23. doi: 10.1016/j.neurobiolaging.2004.03.002

66. Bus BA, Molendijk ML, Penninx BJ, Buitelaar JK, Kenis G, Prickaerts J, et al. Determinants of serum brain-derived neurotrophic factor. Psychoneuroendocrinology (2011) 36:228-39. doi: 10.1016/j.psyneuen.2010. 07.013

67. Zipursky RB, Reilly TJ, Murray RM. The myth of schizophrenia as a progressive brain disease. Schizophr Bull (2013) 39:1363-72. doi: 10.1093/ schbul/sbs135
68. Gardner DM, Murphy AL, O'donnell H, Centorrino F, Baldessarini RJ. International consensus study of antipsychotic dosing. Am J Psychiatry (2010) 167:686-93. doi: 10.1176/appi.ajp.2009.09060802

69. Bullo M, Peeraully MR, Trayhurn P, Folch J, Salas-Salvado J. Circulating nerve growth factor levels in relation to obesity and the metabolic syndrome in women. Eur J Endocrinol (2007) 157:303-10. doi: 10.1530/ EJE-06-0716

70. Bersani G, Iannitelli A, Massoni E, Garavini A, Grilli A, Di Giannantonio M, et al. Ultradian variation of nerve growth factor plasma levels in healthy and schizophrenic subjects. Int J Immunopathol Pharmacol (2004) 17:367-72. doi: $10.1177 / 039463200401700316$

71. Kofanova OA, Mommaerts K, Betsou F. Tube polypropylene: a neglected critical parameter for protein adsorption during biospecimen storage. Biopreserv Biobank (2015) 13:296-8. doi: 10.1089/bio.2014.0082

72. Ashburner J, Friston KJ. Unified segmentation. Neuroimage (2005) 26:83951. doi: 10.1016/j.neuroimage.2005.02.018

73. Ashburner J. A fast diffeomorphic image registration algorithm. Neuroimage (2007) 38:95-113. doi: 10.1016/j.neuroimage.2007.07.007

74. Ashburner J, Friston KJ. Computing average shaped tissue probability templates. Neuroimage (2009) 45:333-41. doi: 10.1016/j.neuroimage.2008. 12.008

75. Mechelli AP, Price CJ, Friston KJ, Ashburner J. Voxel-based morphometry of the human brain: methods and applications. Curr Med Imaging (2005) 1(2):105-113. doi: 10.2174/1573405054038726

76. Nickl-Jockschat T, Rottschy C, Thommes J, Schneider F, Laird AR, Fox PT, et al. Neural networks related to dysfunctional face processing in autism spectrum disorder. Brain Struct Funct (2015) 220:2355-71. doi: 10.1007/ s00429-014-0791-z

77. Eickhoff SB, Stephan KE, Mohlberg H, Grefkes C, Fink GR, Amunts K, et al. A new SPM toolbox for combining probabilistic cytoarchitectonic maps and functional imaging data. Neuroimage (2005) 25:1325-35. doi: 10.1016/j. neuroimage.2004.12.034

78. Eickhoff SB, Heim S, Zilles K, Amunts K. Testing anatomically specified hypotheses in functional imaging using cytoarchitectonic maps. Neuroimage (2006) 32:570-82. doi: 10.1016/j.neuroimage.2006.04.204

79. Eickhoff SB, Paus T, Caspers S, Grosbras MH, Evans AC, Zilles K, et al. Assignment of functional activations to probabilistic cytoarchitectonic areas revisited. Neuroimage (2007) 36:511-21. doi: 10.1016/j.neuroimage.2007. 03.060

80. Laird AR, Eickhoff SB, Li K, Robin DA, Glahn DC, Fox PT. Investigating the functional heterogeneity of the default mode network using coordinatebased meta-analytic modeling. J Neurosci (2009) 29:14496-505. doi: 10.1523/ JNEUROSCI.4004-09.2009

81. Laird AR, Eickhoff SB, Fox PM, Uecker AM, Ray KL, Saenz JJ, Jr., et al. The BrainMap strategy for standardization, sharing, and meta-analysis of neuroimaging data. BMC Res Notes (2011) 4:349. doi: 10.1186/ 1756-0500-4-349

82. Palomero-Gallagher N, Mohlberg H, Zilles K, Vogt B. Cytology and receptor architecture of human anterior cingulate cortex. J Comp Neurol (2008) 508:906-26. doi: 10.1002/cne.21684

83. Amunts K, Malikovic A, Mohlberg H, Schormann T, Zilles K. Brodmann's areas 17 and 18 brought into stereotaxic space-where and how variable? Neuroimage (2000) 11:66-84. doi: 10.1006/nimg.1999.0516

84. Kujovic M, Zilles K, Malikovic A, Schleicher A, Mohlberg H, Rottschy C, et al. Cytoarchitectonic mapping of the human dorsal extrastriate cortex. Brain Struct Funct (2013) 218:157-72. doi: 10.1007/s00429-012-0390-9

85. Morosan P, Rademacher J, Schleicher A, Amunts K, Schormann T, Zilles K. Human primary auditory cortex: cytoarchitectonic subdivisions and mapping into a spatial reference system. Neuroimage (2001) 13:684-701. doi: 10.1006/nimg.2000.0715

86. Morosan P, Schleicher A, Amunts K, Zilles K. Multimodal architectonic mapping of human superior temporal gyrus. Anat Embryol (Berl) (2005) 210:401-6. doi: 10.1007/s00429-005-0029-1

87. Koo MS, Levitt JJ, Salisbury DF, Nakamura M, Shenton ME, Mccarley RW. A cross-sectional and longitudinal magnetic resonance imaging study of cingulate gyrus gray matter volume abnormalities in first-episode schizophrenia and first-episode affective psychosis. Arch Gen Psychiatry (2008) 65:746-60. doi: 10.1001/archpsyc.65.7.746 
88. Nakamura M, Nestor PG, Levitt JJ, Cohen AS, Kawashima T, Shenton ME, et al. Orbitofrontal volume deficit in schizophrenia and thought disorder. Brain (2008) 131:180-95. doi: 10.1093/brain/awm265

89. Takayanagi Y, Takahashi T, Orikabe L, Masuda N, Mozue Y, Nakamura K, et al. Volume reduction and altered sulco-gyral pattern of the orbitofrontal cortex in first-episode schizophrenia. Schizophr Res (2010) 121:55-65. doi: 10.1016/j.schres.2010.05.006

90. Shackman AJ, Salomons TV, Slagter HA, Fox AS, Winter JJ, Davidson RJ. The integration of negative affect, pain and cognitive control in the cingulate cortex. Nat Rev Neurosci (2011) 12:154-67. doi: 10.1038/nrn2994

91. Apps MA, Lockwood PL, Balsters JH. The role of the midcingulate cortex in monitoring others' decisions. Front Neurosci (2013) 7:251. doi: 10.3389/ fnins.2013.00251

92. Bhanji JP, Delgado MR. The social brain and reward: social information processing in the human striatum. Wiley Interdiscip Rev Cogn Sci (2014) 5:61-73. doi: $10.1177 / 039463200401700316$

93. Vogt BA. Midcingulate cortex: structure, connections, homologies, functions and diseases. J Chem Neuroanat (2016) 74:28-46. doi: 10.1016/j. jchemneu.2016.01.010

94. Emanuele E, Politi P, Bianchi M, Minoretti P, Bertona M, Geroldi D. Raised plasma nerve growth factor levels associated with early-stage romantic love. Psychoneuroendocrinology (2006) 31:288-94. doi: 10.1016/j. psyneuen.2005.09.002

95. Emanuele E. NGF and romantic love. Arch Ital Biol (2011) 149:265-8. doi: 10.4449/aib.v149i2.1367

96. Laurent HK, Laurent SM, Granger DA. Salivary nerve growth factor reactivity to acute psychosocial stress: a new frontier for stress research. Psychosom Med (2013) 75:744-50. doi: 10.1097/PSY.0b013e3182a85ffd

97. Salles FH, Soares PS, Wiener CD, Mondin TC, Da Silva PM, Jansen K, et al. Mental disorders, functional impairment, and nerve growth factor. Psychol Res Behav Manag (2017) 10:9-15. doi: 10.2147/PRBM.S104814

98. Billeke P, Aboitiz F. Social cognition in schizophrenia: from social stimuli processing to social engagement. Front Psychiatry (2013) 4:4. doi: 10.3389/ fpsyt.2013.00004

99. Bonnot O, Anderson GM, Cohen D, Willer JC, Tordjman S. Are patients with schizophrenia insensitive to pain? A reconsideration of the question. Clin J Pain (2009) 25:244-52. doi: 10.1097/AJP.0b013e318192be97

100. Levesque M, Potvin S, Marchand S, Stip E, Grignon S, Pierre L, et al. Pain perception in schizophrenia: evidence of a specific pain response profile. Pain Med (2012) 13:1571-9. doi: 10.1111/j.1526-4637.2012.01505.x

101. Engels G, Francke AL, Van Meijel B, Douma JG, De Kam H, Wesselink W, et al. Clinical pain in schizophrenia: a systematic review. J Pain (2014) 15:457-67. doi: 10.1016/j.jpain.2013.11.005

102. Seidel MF, Wise BL, Lane NE. Nerve growth factor: an update on the science and therapy. Osteoarthr Cartil (2013) 21:1223-8. doi: 10.1016/j.joca.2013.06.004

103. Chang DS, Hsu E, Hottinger DG, Cohen SP. Anti-nerve growth factor in pain management: current evidence. J Pain Res (2016) 9:373-83. doi: 10.2147/ JPR.S89061

104. Bannwarth B, Kostine M. Targeting nerve growth factor (NGF) for pain management: what does the future hold for NGF antagonists? Drugs (2014) 74:619-26. doi: 10.1007/s40265-014-0208-6

105. Jockers-Scherubl MC, Matthies U, Danker-Hopfe H, Lang UE, Mahlberg R, Hellweg R. Chronic cannabis abuse raises nerve growth factor serum concentrations in drug-naive schizophrenic patients. J Psychopharmacol (2003) 17:439-45. doi: 10.1177/0269881103174007

106. Hawrylycz MJ, Lein ES, Guillozet-Bongaarts AL, Shen EH, Ng L, Miller JA, et al. An anatomically comprehensive atlas of the adult human brain transcriptome. Nature (2012) 489:391-9. doi: 10.1038/nature11405

107. Ernst M, Paulus MP. Neurobiology of decision making: a selective review from a neurocognitive and clinical perspective. Biol Psychiatry (2005) 58:597-604. doi: 10.1016/j.biopsych.2005.06.004

108. Kuperberg GR. Language in schizophrenia part 1: an introduction. Lang Linguist Compass (2010) 4:576-89. doi: 10.1111/j.1749-818X.2010.00216.x

109. Walther S, Strik W. Motor symptoms and schizophrenia. Neuropsychobiology (2012) 66:77-92. doi: 10.1159/000339456
110. Radanovic M, Sousa RT, Valiengo L, Gattaz WF, Forlenza OV. Formal thought disorder and language impairment in schizophrenia. Arq Neuropsiquiatr (2013) 71:55-60. doi: 10.1590/S0004-282X2012005000015

111. Green MF, Horan WP, Lee J. Social cognition in schizophrenia. Nat Rev Neurosci (2015) 16:620-31. doi: 10.1038/nrn4005

112. Dowiasch S, Backasch B, Einhauser W, Leube D, Kircher T, Bremmer F. Eye movements of patients with schizophrenia in a natural environment. Eur Arch Psychiatry Clin Neurosci (2016) 266:43-54. doi: 10.1007/ s00406-014-0567-8

113. Dutschke LL, Stegmayer K, Ramseyer F, Bohlhalter S, Vanbellingen T, Strik $\mathrm{W}$, et al. Gesture impairments in schizophrenia are linked to increased movement and prolonged motor planning and execution. Schizophr Res (2017) 200:42-9. doi: 10.1016/j.schres.2017.07.012

114. Robberegt S, Fett A-K. M21. Social reward learning deficits in patients with schizophrenia. Schizophr Bull (2017) 43:219. doi: 10.1093/schbul/sbx022.020

115. Onitsuka T, Mccarley RW, Kuroki N, Dickey CC, Kubicki M, Demeo SS, et al. Occipital lobe gray matter volume in male patients with chronic schizophrenia: a quantitative MRI study. Schizophr Res (2007) 92:197-206. doi: 10.1016/j.schres.2007.01.027

116. Figley CR, Asem JS, Levenbaum EL, Courtney SM. Effects of body mass index and body fat percent on default mode, executive control, and salience network structure and function. Front Neurosci (2016) 10:234. doi: 10.3389/ fnins.2016.00234

117. Buckley PF, Mahadik S, Pillai A, Terry A, Jr. Neurotrophins and schizophrenia. Schizophr Res (2007) 94:1-11. doi: 10.1016/j.schres.2007.01.025

118. Negrini S, D'alessandro R, Meldolesi J. NGF signaling in PC12 cells: the cooperation of p75(NTR) with TrkA is needed for the activation of both mTORC2 and the PI3K signalling cascade. Biol Open (2013) 2:855-66. doi: 10.1242/bio.20135116

119. Sala R, Viegi A, Rossi FM, Pizzorusso T, Bonanno G, Raiteri M, et al. Nerve growth factor and brain-derived neurotrophic factor increase neurotransmitter release in the rat visual cortex. Eur J Neurosci (1998) 10:2185-91. doi: 10.1046/j.1460-9568.1998.00227.x

120. Paredes D, Granholm AC, Bickford PC. Effects of NGF and BDNF on baseline glutamate and dopamine release in the hippocampal formation of the adult rat. Brain Res (2007) 1141:56-64. doi: 10.1016/j.brainres.2007.01.018

121. Numakawa T, Nakayama H, Suzuki S, Kubo T, Nara F, Numakawa $Y$, et al. Nerve growth factor-induced glutamate release is via p75 receptor, ceramide, and $\mathrm{Ca}(2+)$ from ryanodine receptor in developing cerebellar neurons. J Biol Chem (2003) 278:41259-69. doi: 10.1074/jbc. M304409200

122. Javitt DC. Glutamatergic theories of schizophrenia. Isr J Psychiatry Relat Sci (2010) 47:4-16.

123. Paoletti P, Neyton J. NMDA receptor subunits: function and pharmacology. Curr Opin Pharmacol (2007) 7:39-47. doi: 10.1016/j.coph.2006.08.011

124. Marsman A, Van Den Heuvel MP, Klomp DW, Kahn RS, Luijten PR, Hulshoff Pol HE. Glutamate in schizophrenia: a focused review and metaanalysis of (1)H-MRS studies. Schizophr Bull (2013) 39:120-9. doi: 10.1093/ schbul/sbr069

125. Natsubori T, Inoue H, Abe O, Takano Y, Iwashiro N, Aoki Y, et al. Reduced frontal glutamate + glutamine and $\mathrm{N}$-acetylaspartate levels in patients with chronic schizophrenia but not in those at clinical high risk for psychosis or with first-episode schizophrenia. Schizophr Bull (2014) 40:1128-39. doi: $10.1093 /$ schbul/sbt124

126. Howes O, Mccutcheon R, Stone J. Glutamate and dopamine in schizophrenia: an update for the 21st century. J Psychopharmacol (2015) 29:97-115. doi: $10.1177 / 0269881114563634$

127. Weickert CS, Hyde TM, Lipska BK, Herman MM, Weinberger DR, Kleinman JE. Reduced brain-derived neurotrophic factor in prefrontal cortex of patients with schizophrenia. Mol Psychiatry (2003) 8:592-610. doi: 10.1038/ sj.mp. 4001308

128. Lang UE, Gallinat J, Danker-Hopfe H, Bajbouj M, Hellweg R. Nerve growth factor serum concentrations in healthy human volunteers: physiological variance and stability. Neurosci Lett (2003) 344:13-6. doi: $10.1055 / \mathrm{s}-2003-825418$ 
129. Vega JA, Garcia-Suarez O, Hannestad J, Perez-Perez M, Germana A. Neurotrophins and the immune system. J Anat (2003) 203:1-19. doi: 10.1046/j.1469-7580.2003.00203.x

130. Rosenfeld RD, Zeni L, Haniu M, Talvenheimo J, Radka SF, Bennett L, et al. Purification and identification of brain-derived neurotrophic factor from human serum. Protein Expr Purif (1995) 6:465-71. doi: 10.1006/prep.1995.1062

131. Bonini S, Rasi G, Bracci-Laudiero ML, Procoli A, Aloe L. Nerve growth factor: neurotrophin or cytokine? Int Arch Allergy Immunol (2003) 131:80-4. doi: $10.1159 / 000070922$

132. Noga O, Englmann C, Hanf G, Grutzkau A, Seybold J, Kunkel G. The production, storage and release of the neurotrophins nerve growth factor, brain-derived neurotrophic factor and neurotrophin-3 by human peripheral eosinophils in allergics and non-allergics. Clin Exp Allergy (2003) 33:649-54. doi: 10.1046/j.1365-2222.2003.01586.x

133. Hochstrasser T, Ehrlich D, Sperner-Unterweger B, Humpel C. Antidepressants and anti-inflammatory drugs differentially reduce the release of NGF and BDNF from rat platelets. Pharmacopsychiatry (2013) 46:29-34. doi: 10.1055/s-0032-1314843

134. Kniewallner KM, Grimm N, Humpel C. Platelet-derived nerve growth factor supports the survival of cholinergic neurons in organotypic rat brain slices. Neurosci Lett (2014) 574:64-9. doi: 10.1016/j.neulet.2014.05.033

135. Parikh V, Evans DR, Khan MM, Mahadik SP. Nerve growth factor in nevermedicated first-episode psychotic and medicated chronic schizophrenic patients: possible implications for treatment outcome. Schizophr Res (2003) 60:117-23. doi: 10.1016/S0920-9964(03)80679-5

136. Parikh V, Khan MM, Terry A, Mahadik SP. Differential effects of typical and atypical antipsychotics on nerve growth factor and choline acetyltransferase expression in the cortex and nucleus basalis of rats. J Psychiatr Res (2004) 38:521-9. doi: 10.1016/j.jpsychires.2004.03.008
137. Jockers-Scherubl MC, Rentzsch J, Danker-Hopfe H, Radzei N, Schurer F, Bahri S, et al. Adequate antipsychotic treatment normalizes serum nerve growth factor concentrations in schizophrenia with and without cannabis or additional substance abuse. Neurosci Lett (2006) 400:262-6. doi: 10.1016/j. neulet.2006.02.056

138. Pillai A, Terry AV, Jr., Mahadik SP. Differential effects of long-term treatment with typical and atypical antipsychotics on NGF and BDNF levels in rat striatum and hippocampus. Schizophr Res (2006) 82:95-106. doi: 10.1016/j. schres.2005.11.021

139. Fiore M, Di Fausto V, Iannitelli A, Aloe L. Clozapine or haloperidol in rats prenatally exposed to methylazoxymethanol, a compound inducing entorhinal-hippocampal deficits, alter brain and blood neurotrophins' concentrations. Ann Ist Super Sanita (2008) 44:167-77.

140. Gioiosa L, Iannitelli A, Aloe L. Stress, anxiety and schizophrenia and neurotrophic factors: the pioneer studies with nerve growth factor. Riv Psichiatr (2009) 44:88-94.

Conflict of Interest Statement: The authors declare that the research was conducted in the absence of any commercial or financial relationships that could be construed as a potential conflict of interest.

Copyright (C) 2019 Neugebauer, Hammans, Wensing, Kumar, Grodd, Mevissen, Sternkopf, Novakovic, Abel, Habel and Nickl-Jockschat. This is an open-access article distributed under the terms of the Creative Commons Attribution License (CC BY). The use, distribution or reproduction in other forums is permitted, provided the original author(s) and the copyright owner(s) are credited and that the original publication in this journal is cited, in accordance with accepted academic practice. No use, distribution or reproduction is permitted which does not comply with these terms. 